\title{
Wear of Different PVD Coatings at Industrial Fine-blanking Field Tests
}

\author{
Liina LIND*, Priidu PEETSALU, Fjodor SERGEJEV
}

Tallinn University of Technology, Department of Materials Engineering, Ehitajate tee 5, 19086 Tallinn, Estonia

crossref http://dx.doi.org/10.5755/j01.ms.21.3.7249

Received 05 June 2014; accepted 13 July 2014

\begin{abstract}
Thin hard physical vapor deposited (PVD) coatings play significant role on wear performance of fine-blanking punches in the presence of extremely high contact stresses. Nevertheless it seems that in blanking or fine-blanking the coatings are selected based on coincidence, trial-error-method or latest trends. There is limited information about planning and conducting the fine-blanking industrial field tests and measuring the wear of different coatings. In the present study a set of fine-blanking punches and laboratory specimens were prepared with three coatings - TiCN, nACRo and nACo. As substrate material Böhler S390 Microclean high speed steel was used. Coating mechanical properties (modulus of elasticity and nanohardness) were measured and wear rate with alumina ball was determined using the reciprocating sliding test. Wear of coatings was measured from punches after industrial use. All of the tested coatings showed high variance of wear. However coatings nACo and nACRo have better average wear resistance in fine-blanking compared with the well-known TiCN. Industrial field tests show correlation to the ratio elastic strain to failure H/E.

Keywords: PVD coating, wear, fine-blanking, industrial field test.
\end{abstract}

\section{INTRODUCTION}

During fine-blanking process contact stress around $3000 \mathrm{MPa}$ and temperatures about $400{ }^{\circ} \mathrm{C}$ may be generated in the front face of the punches [1] setting high demands for the hard coatings and tools. Therefore PVD coatings with optimized properties are required. Previous studies have reported that from mechanical properties point-of-view low modulus of elasticity of coatings is desired accompanied with high hardness [2-5] providing good wear resistance and better performance. Foremost, coatings are expected to have low modulus of elasticity $[6,7]$. Multilayered structure of coatings is favoured since it provides resistance against crack development inside the coating and can decrease the modulus of elasticity [2, 3].

The studies concerning fine-blanking are quite often based on theoretical hypothesis, analytical studies or FEM modelling which are verified through industrial tests. However, information regarding industrial test planning, setup and results analysis are not always thoroughly described. For example, there are studies reporting results achieved from industrial field tests concerning blanking [8] or fine-blanking [9] stating that certain coatings have advantages against the others; however data regarding the compared coating thickness, coating adhesion or tools specification is not discussed in depth. Straffelini et al. [5] have presented an interesting study about the shaving step in fine-blanking involving punches with different preparation techniques, nevertheless effect of different PVD coatings are not discussed. Furthermore, Klocke et al. [2] reports using TiN and TiAlN for fine-blanking punches without lubrication, however the focus of the study is on lubricants and different coatings for fine-blanking are not compared based on their lifetime.

For assessing coating performance it is important to test the coatings in a tribological system which is as close

\footnotetext{
${ }^{*}$ Corresponding author. Tel.: +372-6203353; fax: +372-6202020.

E-mail address: liina.lind@ttu.ee (L. Lind)
}

to the application as possible. The present paper is a development of an industrial field test to describe wear resistance of different coatings on fine-blanking punches. The developed industrial field test is used to demonstrate the performance of three different PVD coatings using the six-row fine-blanking tool. The planning and conducting of the field tests together with measuring wear of different coatings is presented. The proposed method has been partially employed in our previous studies $[10,11]$ however the technique has been improved since then, and this is the first time the industrial field test method will be described in full extent.

\section{EXPERIMENTAL DETAILS}

\subsection{Laboratory specimen preparation}

Coatings were deposited on polished $(\mathrm{Ra}=0.004 \mu \mathrm{m})$ specimens from hardmetal WC-Co (10 wt\% Co) and Böhler P/M S390 Microclean high speed steel (HSS) with hardness 65 HRC. Hardmetal substrates were used for determination of modulus of elasticity (E) and nanohardness $(\mathrm{H})$ of the coatings. High $\mathrm{E}$ and $\mathrm{H}$ of the hardmetal are beneficial in avoiding substrate deformation during instrumented indentation.

\subsection{Industrial tools preparation}

Fine-blanking punches were manufactured from Böhler P/M S390 Microclean HSS, heat treated and annealed to hardness $64 \mathrm{HRC}$. Punches were wire-cut to shape using electric discharge machining (EDM). The "white layer" formed during EDM was removed by manual microblasting of the punches. Achieved surface roughness $\mathrm{Ra}$ for the punches was $0.6-0.9 \mu \mathrm{m}$.

\subsection{Coating deposition procedure}

Hard coatings TiCN, nACro $\left(\mathrm{AlCrN} / \mathrm{Si}_{3} \mathrm{~N}_{4}\right)$ and nACo $\left(\mathrm{AlTiN} / \mathrm{Si}_{3} \mathrm{~N}_{4}\right)$ were deposited using PVD equipment 
Platit $\pi 80$ with Lateral Rotating ARC-Cathode technology. Prior to deposition laboratory specimens and industrial punches were cleaned in ultrasonic bath with isopropanol. Immediately after the cleaning procedure objects were placed into the vacuum chamber and sputter-cleaned in argon plasma. The deposition temperature was in the range of $450{ }^{\circ} \mathrm{C}$ for each coating.

\subsection{Coating characterization}

Nanohardness and modulus of elasticity (see Table 1) were measured from coatings deposited onto polished WCCo substrates using MTS Nano Indenter XP. Indentations were done with a new Berkovich indenter using loads of 20, 30 and $50 \mathrm{mN}$ in series of minimum 20 qualified measurements. Modulus of elasticity was calculated according to Oliver-Pharr [12] and CEN/TS [13] procedure.

Rockwell indentation method $[14,15]$ was used to evaluate coatings adhesion (see Table 1) on polished HSS substrates. Coating thicknesses (Table 1) were measured from the same specimens using the ball-cratering equipment Kalotester KaloMax.

Wear rate of coatings on polished HSS substrates was determined using standard method [16] with the universal tribometer CETR UMT-2 and alumina ball, which enables to characterize the coating wear behavior in abrasive situation [17]. The experiments were carried out at room temperature and relative humidity of $55 \%$. Reciprocating sliding mode was used with alumina counter body with diameter of $10 \mathrm{~mm}$, contact load of $9.81 \mathrm{~N}$, reciprocating distance of $2 \mathrm{~mm}$ and sliding frequency of $5 \mathrm{~Hz}$ (average speed $20 \mathrm{~mm} / \mathrm{s}$ ). Hertzian initial point mean contact pressure was 1.5-2 GPa dependent on the coating. Testing time varied from 5 to 10 minutes due to great differences between wear rates of different coatings. The testing time was shortened to 5 minutes for the nACo coating to avoid wear through the coating and the time was 10 minutes for TiCN and nACRo to achieve a measurable wear track. Depths of the wear tracks were measured using a 3D optical surface profilometer ContourGT-I from Bruker. Wear tests were repeated 3 times. Wear rate of coatings is presented in Table 1.

\subsection{Industrial field tests}

The tests were carried out in a 6 row progressive type tool with the hydraulic fine-blanking press HFA 4500 plus from Feintool and the steel strip material was S420MC with nominal thickness of $2.4 \mathrm{~mm}$ and tensile strength $550 \pm 70 \mathrm{MPa}$. Coatings TiCN, nACRo and nACo were applied on a set of 6 cutting punches i.e. 2 punches per coating. The set of punches was working at the same time. A special fine-blanking lubricant was used supplied by W.L. TriboTechnik.

The experimental fine-blanking punches were complex-shaped. The exact shape is confidential information. However the outline consisted of a flat line, and two different curvatures presented in Fig. 1 a. The size of the face of the punches could be fitted into a $10 \times 15 \mathrm{~mm}$ size rectangle. Height of the punches varied from 70-90 mm depending on the number of times the punch was used i.e. after each test the tools are reconditioned by grinding off the tip of the punch. Nevertheless, the set of punches had the same height at all tests because they were reconditioned uniformly.

Side view of the punch is presented in Fig. $1 \mathrm{~b}$, which is in sliding contact with the steel strip during fineblanking. Cutting edge of the punch is subjected to wear and during reconditioning it is removed. Worn area of the coating was considered to be equal to the surface area of revealed substrate of the punch (coating failed area). The measurement location and gauge i.e. the length of the wear measurement was always constant following the cutting edge of the punch. The gauge was chosen to be $5.7 \mathrm{~mm}$. Fig. $1 \mathrm{~b}$ presents the scheme of worn area measurement. Sometimes the punch exhibits areas of small discrete coating detachment, which are not always visible with optical microscopy (at Fig. 1 the areas are exaggerated in size). However these areas are excluded from the worn area calculation. The worn punches were photographed using the stereomicroscope ZEISS Discovery V20 and the worn areas were measured with OmniMet image analysis software from Buehler.

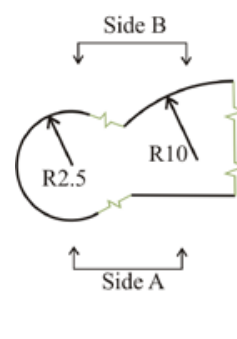

a

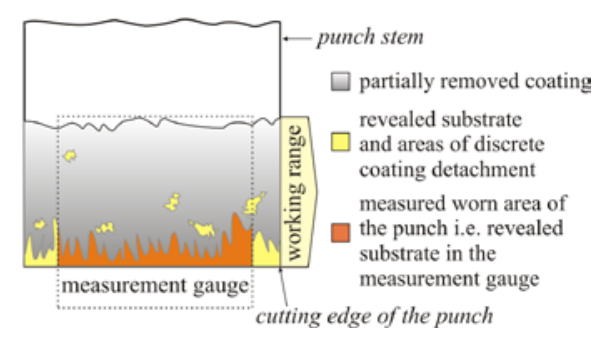

$\mathrm{b}$
Fig. 1. Fraction of the face of the selected punch with representative side $\mathrm{A}$ and $\mathrm{B}$, radius $\mathrm{R}$ is given in $\mathrm{mm}$ (a) and scheme of the coating wear measurement (b)

\section{RESULTS AND DISCUSSION}

\subsection{Prediction of wear of the PVD coatings}

PVD coatings are of significant importance at fineblanking. To achieve better wear resistance constant development of the coatings is done. However for that understanding the connections between coating properties and wear resistance during fine-blanking is of key importance. The practical applicability of the PVD coatings is dependent on the order of magnitude of their main mechanical properties, such as hardness $(\mathrm{H})$, modulus of elasticity (E), not only showing the coatings characteristics, but allowing to assess and compare coatings wear resistance on the basis of hardness to elastic modulus ratios. The hardness to elastic modulus ratios can be used to describe not only "elastic", but the "plastic" behaviour of the coating.

Previously published work of Leyland [6] describes the importance of the hardness to elastic modulus ratio and the effect of the higher ratios on the wear resistance of the coatings, allowing to conclude that the higher $\mathrm{H} / \mathrm{E}$ ratio of the coating leads to reduction in wear, assumed that hardness is sufficently high. The elastic modulus should be adjusted to closely match that of the underlying substrate material, thus minimasing coating/substrate interfacial stress discontinuities under an applied load, allowing the 
Table 1. Properties of the PVD coatings

\begin{tabular}{|c|c|c|c|c|c|c|}
\hline Coating & Coating type & $\begin{array}{c}\text { Modulus of } \\
\text { elasticity, GPa }\end{array}$ & Nanohardness, GPa & Coating thickness, $\mu \mathrm{m}$ & $\begin{array}{c}\text { Adhesion } \\
\text { class }\end{array}$ & $\begin{array}{c}\text { Wear rate, } \\
10^{-6} \mathrm{~mm}^{3} / \mathrm{Nm}\end{array}$ \\
\hline TiCN & gradient & $494 \pm 24$ & $31.9 \pm 1.4$ & 3.5 & HF2 & 0.25 \\
nACRo & $\begin{array}{c}\text { gradient } \\
\text { (nanocomposite) }\end{array}$ & $429 \pm 16$ & $29.3 \pm 0.6$ & 3.3 & HF3 & 0.22 \\
\hline nACo & $\begin{array}{c}\text { multilayer } \\
\text { (nanocomposite) }\end{array}$ & $367 \pm 8$ & $25.3 \pm 1.9$ & 2.5 & HF3 & 7.59 \\
\hline
\end{tabular}

coating to deform together with the substrate without cracking or debonding. Leyland calls the $\mathrm{H} / \mathrm{E}$ ratio as elastic strain to failure.

In the work of Musil it has been proved that the $\mathrm{H} / \mathrm{E}$ ratio can be related to the elastic recovery $W e$, the elasticenergy for deformation, showing that coating with different hardness can exhibit same elastic recovery, providing approximately constant $\mathrm{H} / \mathrm{E}$ ratios for different coatings [18]. This is why the different hardness to elastic modulus ratios should be used for better coating characterization.

The resistance to plastic indentation in the form of $\mathrm{H} / \mathrm{E}^{2}$ is a measure of the materials resistance to plastic penetration, and expected to correlate better with resistance to abrasive and erosive wear than either the hardness or the elastic modulus separately [19]. The high $\mathrm{H} / \mathrm{E}^{2}$ ratio is the indication of the material's better ability to resist permanent damage. As this mechanical property is only related to the contact area between two bodies, like blanking tool (punch) and workpiece (sheet metal), the higher the ratio is the higher load can be sustained without plastic deformation. The ratio $\mathrm{H} / \mathrm{E}^{2}$ allows as to compare coatings ability to resist local plastic deformation caused by abrasive particles at the punch and sheet metal interface.

Tsui et al. [20] describes the $\mathrm{H}^{3} / \mathrm{E}^{2}$ ratio as resistance to plastic deformation and as the best measure to correlate the mechanical properties to wear resistance of the hard coatings. Higher resistance to plastic deformation ratio means higher ability of coating to dissipate energy due to plastic deformation during loading.

The studied TiCN, nACo and nACRo thin hard coatings hardness to elastic modulus ratios, shown in Fig. 2, should not be analysed alone; e.g. in the case of $\mathrm{H} / \mathrm{E}$ ratio the dimentional dissimilarity between coatings is too small for comparison. The measure of the resistance to plastic indentation $\mathrm{H} / \mathrm{E}^{2}$ provides distinguished comparison of the coatings, and leads to conclusion that nACo coating has the tendency to higher abrasive and erosive wear resistance among studied coatings. However the resistance to plastic deformation $\left(\mathrm{H}^{3} / \mathrm{E}^{2}\right)$ of nACo coating is lowest, if compared with TiCN and nACRo coatings. If all three ratios are taken into consideration the nACRo coating seems to be the most promising candidate for highest performance in the conditions of intensive abrasion and erosion wear.

Another commonly known test to describe the coating properties is the reciprocating sliding test. The results of coating wear rate, see Table 1 , are confirming the suitability of hardness to elastic modulus ratios concept to characterise the wear properties of the coatings. Coating wear rates (Table 1) show that nACo was far most susceptive to wear during dry reciprocating sliding, while nACRo and TiCN demonstrate relatively low wear. However, the wear rate with alumina is in great disagreement with wear ratios $\mathrm{H} / \mathrm{E}$ and $\mathrm{H} / \mathrm{E}^{2}$ indicating that nACo should have better wear resistance than TiCN or nACRo (Fig. 2). The reason for this could be the nACo has lowest hardness. Wear rate from reciprocating sliding test is in good agreement with resistance to plastic deformation $\left(\mathrm{H}^{3} / \mathrm{E}^{2}\right)$ ratios (see Fig. 2). This indicates that applied contact pressure at the reciprocating sliding test has probably exceeded the elastic deformation limit of the nACo coating at the largest extent.

In conclusion, nACRo seems to be advantageous considering to the superior relations of the hardness to elastic modulus.

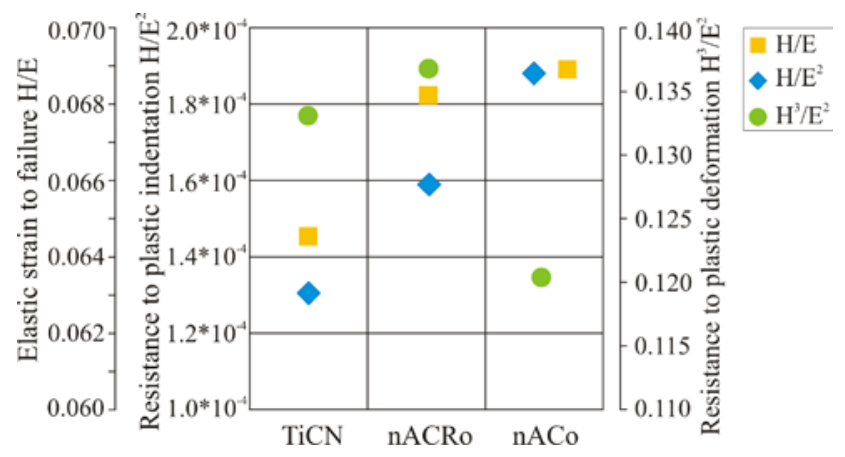

Fig. 2. Characteristic ratios of the selected PVD coatings

\subsection{Selection of the tool for the industrial field tests}

Lifetime of the tool is commonly assessed by the number of strokes made before defects appear on the product caused by wear, chipping or fracture of the tools. To find suitable tools for testing PVD coatings an analysis concerning production of 4 different components over a 2 year period was carried out based on the database records. The average number of strokes and the main failure reasons for the selected components were studied.

For testing the coating wear resistance it is preferred to have tools where the failure is commonly associated with formation of burr. Burr arises on the component when the clearance between the punch and the die exceeds the set value i.e. circumference of the punch cutting edge decreases or of the die increases. One of the main reasons for increase in the clearance is wear of the punch. Therefore for the industrial field test a tool was selected where the probability of burr was $38 \%$ and chipping $13 \%$, the average number of strokes between maintenance was 8600. All statistics are given over a 2 year period. 


\subsection{Assurance of the same working conditions of different coatings during the industrial field tests}

PVD coating wear resistance measurements in the field are essential to understand coating behaviour in its application. Measuring the wear resistance of the different coatings it is critical to assure same working conditions for all coatings. At the industrial scale there are many variables which are difficult to control, e.g. variations between different batches of the sheet metal, positioning accuracy (assembly), lubrication conditions and the tool operator. We have employed following means to ensure that testing of different coatings in industrial situation is conducted under comparable conditions:

- The heat treatment, EDM, micro-blasting and handling was alike for the set of 6 test punches.

- A 6-row progressive tool enables using six punches which are working at the same time in similar conditions. Wear is converted into relative percentage (see chapter 3.4). This measure excludes possible variations in sheet metal batch, press type, factory temperature and the operator. Furthermore, having 6 punches in the tool allowed us to test three different coatings and to have two punches per each coating.

- Repetitive tests were conducted. One single test may give misleading results. Furthermore, fully coated punches may behave differently than the reconditioned ones i.e. tip of the punch is left uncoated after reconditioning. In ideal coatings should have good lifetime with both occasions.

- Rearranging the punches with different coatings in between repetitive tests. Variations in wear might be caused by specific rows therefore it's necessary to rearrange the punches.

\subsection{Industrial field tests}

Because of the complex shape of the selected punch it was required to consider several places for coating wear measurement (Fig. 3 and Fig. 1).

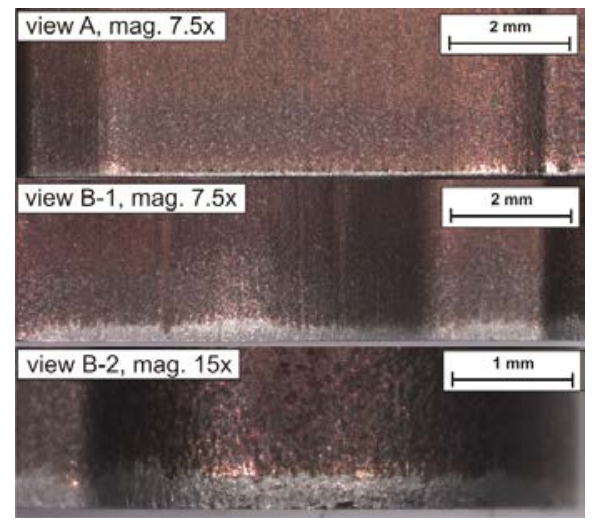

Fig. 3. Industrial worn punch coated with TiCN. The topmost view $\mathrm{A}$ is from side $\mathrm{A}$ and views $\mathrm{B}-1$ and $\mathrm{B}-2$ represent side $B$, radius $100 \mathrm{~mm}$ and $25 \mathrm{~mm}$ respectively

Light from the microscope was able to illuminate the flat side A without formation of shadows and focusing was easy. However it was found that side A was less affected by wear when compared to side B (Fig. 3). Variations between wear of different coatings were not detectable from side A. Furthermore two magnifications were considered, mag. $15 \mathrm{x}$ enabled clearer vision of wear boundary. However the curvature of the punch in view B-2 was too great to enable focusing the entire surface and also it was better to include a larger area because of the possible variations in wear height along the cutting edge. In conclusion, view B-1 with magnification $7.5 \mathrm{x}$ was selected for analysis and all the following results are based on wear measured from that view.

Between repetitive tests worn areas of the PVD coatings should not be directly compared and averaged since the number of strokes varied from 20500 to 45000 . To enable comparing results worn areas were converted into relative wear percentage. For each test the most worn punch with area $a_{\max }$ was determined and referred to as $100 \%$ wear. With the repetitive experiments it was revealed that in row 1 (R1) wear was always almost two times higher (see Fig. 4). Therefore $a_{\max }$ is determined from rows 2-6 excluding R1. Relative wear of the coating $w_{\mathrm{i}}$ was calculated according to Eq. (1), where $a_{\mathrm{i}}$ is the worn area of the punch in row $i(i=2-6)$.

$$
w_{i}=\frac{a_{i} \cdot 100}{a_{\max }} .
$$

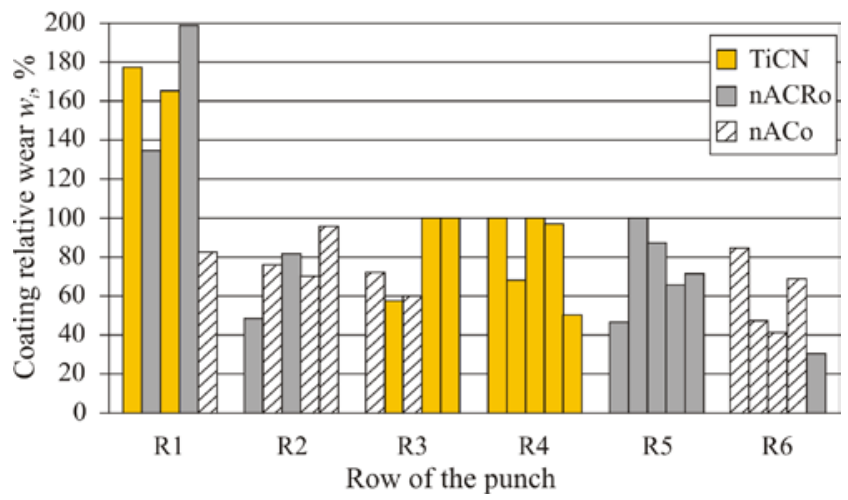

Fig. 4. Wear results throughout the 5 field tests. For each row 5 columns is given representing the test no. $1-5$ from left to right, respectively

Fig. 4 presents the relative wear data as raw data from 5 repetitive industrial field tests made with a six-row (R1-R6) tool. Each repetitive test consists of results from six punches with three coatings. Coatings are shown in Fig. 4 with different colour and pattern scheme. Coated punches are rearranged in between the repetitive trials to achieve reliable results and that is the reason why each row (R) consists of different coating columns. At field test no. 5 the wear in R1 is comparable with other rows. Reason for this is likely connected to the changed guide plate. Further analysis neglects results from R1 concerning field tests 1-4 since increased wear at these tests in that specific row is most likely caused by the tool setup or design and not strictly related to the coating composition or properties.

The quantitative analysis of the data in Fig. 4 is given in Fig. 5 in the form of the average, median and upperlower limits of wear for the tested coatings. Average and median value of the well-known TiCN coating shows highest wear however it is difficult to differentiate 

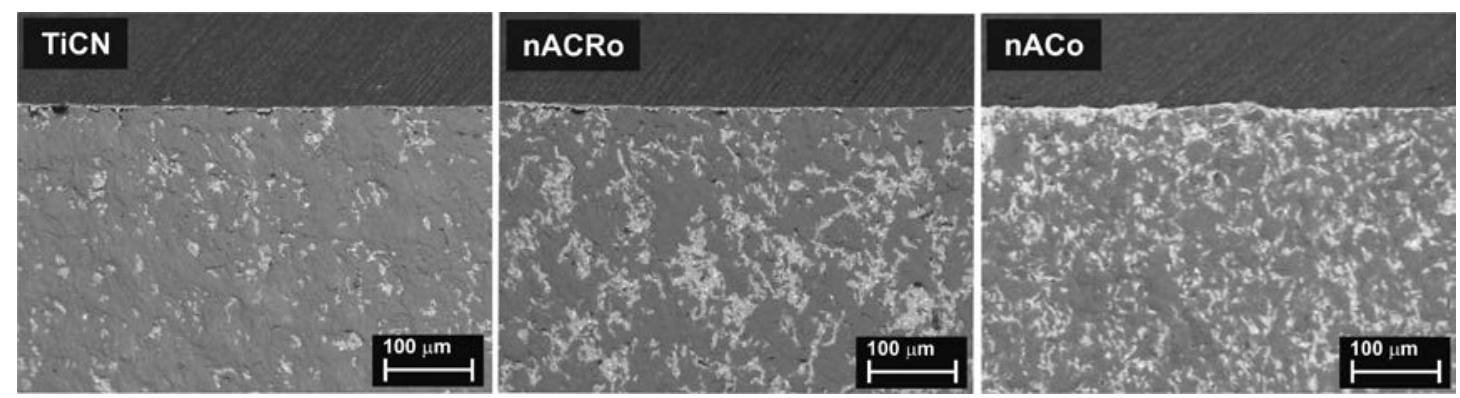

Fig. 6. SEM of punches after the reconditioning procedure

nanocomposite nACRo from nACo. The nACRo coating showed unstable behaviour by having excellent wear resistance at some tests while being the poorest at other tests. TiCN can also be good at some tests however using only the TiCN coatings at the production would probably result in decrease of the overall punch lifetime compared with nACRo or nACo.

From Fig. 5 it could be estimated that the difference between average wear of the coatings is $14-17 \%$. Comparing only the minimum relative wear values of coatings the difference between the best (nACRo) and worst (TiCN) punch is somewhat higher reaching $19 \%$. However comparing only the maximum relative wear values the difference between nACo (best) and TiCN (worst) is only $5 \%$.

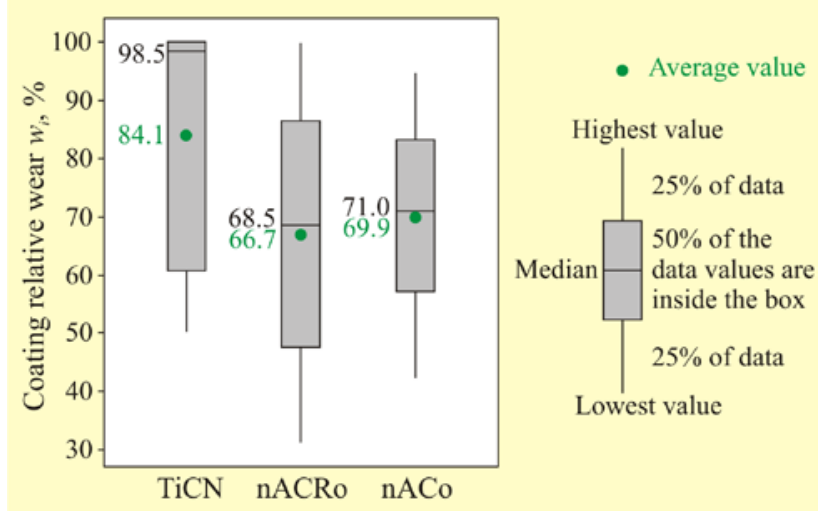

Fig. 5. Relative wear of coatings at repetitive industrial field tests

Statistical analysis presented in Fig. 5 shows high variation of the industrial tests and importance to have repetitive tests as one test could give misleading results even though the punches are working in similar conditions. Furthermore coating wear rate may change during its lifetime (which is approximately 10 reconditioning's).

In between the repetitive trials the tips of the punches are ground i.e. reconditioned. Aim of the reconditioning procedure is to remove the visibly worn areas of the punch cutting edge. However the sheet strip thickness (i.e. working range of the punch) is several times higher compared to the worn area height (see Fig. $1 \mathrm{~b}$ ). Hence the reconditioned punch working range coincides with the working range at the previous operation. Therefore with reconditioned punches the coating close to the cutting edge is not new but already worn (Fig. 6). Since the reconditioning is done several times it is inevitable that reconditioned punch coating close to the cutting edge has already wear marks and therefore wear rate of the individual studied coatings can change. Coating showing good results in a new state may wear with increased rate at the reconditioned state.

The goal of industrial field test development is to get reliable information about coating behaviour in the actual tribological contact (at fine-blanking punch) and use the information to select and develop coatings. The industrial fine-blanking field tests show correlation to the ratio elastic strain to failure H/E (Fig. 2). Coatings nACo and nACRo show better resistance to the failure than TiCN. Accordingly it is not important to have high hardness of the coating but low elastic modulus (close to the substrate material) to keep the stresses inside coating low. There is no connection of the industrial field tests with the reciprocating sliding test with $\mathrm{Al}_{2} \mathrm{O}_{3}$ ball and also there is no direct connection to resistance to plastic indentation $\left(\mathrm{H} / \mathrm{E}^{2}\right)$ and resistance to plastic deformation $\left(\mathrm{H}^{3} / \mathrm{E}^{2}\right)$.

\subsection{Industrial field test uncertainty}

Relative wear of each coating varied between rows and different tests within a wide range (Fig. 5) extending from $50 \%$ up to $70 \%$ difference between upper and lower relative wear values. There could be many reasons for this dispersion. One reason could be positioning or wear of the punch guide plates. However in case of positioning errors one side of the punch would suffer from higher wear than the other. Yet, this was not the case since both sides of the punch were always checked and such positioning errors were not noticed. Most likely the high dispersion in results is connected to the punch preparation, i.e. EDM treatment and micro-blasting (pre-treatment) prior to the PVD coating process. Substrates of the punches were manually microblasted before the coating deposition. With manual blasting it is difficult to guarantee that the topography will be uniform. Moreover, impurities on the substrate i.e. particles from microblasting which are embedded into the surface may be the cause for cracking and detachment of discrete coating areas [21, 22].

Future work should consider better control over the preparation of punches. Excluding coating adhesion variations derived from the EDM process or the following abrasive treatment needs increased attention. This includes removal of the "white layer", controlling the surface topography, efficient cleaning of the punch surface prior to PVD coating deposition.

\section{CONCLUSIONS}

A wear measuring method for industrial tools is proposed enabling comparing results obtained from different industrial field tests and eliminating factors, 
which are not always constant (e.g. number of strokes, steel batch). The technique is relatively simple however visible wear of the coatings and multiple row tool are required for using the method. The proposed industrial method has potential to be implemented with research involving influence of surface topography, coating thickness and also with different substrate materials to assess the wear performance. To decrease uncertainty of the industrial field tests great attention should be directed to preparation of the tools e.g. uniform removal of the white layer formed at the EDM treatment.

Industrial field tests with fine-blanking punches included three PVD coatings TiCN, $\mathrm{AlCrN} / \mathrm{Si}_{3} \mathrm{~N}_{4}$ (nACRo) and $\mathrm{AlTiN} / \mathrm{Si}_{3} \mathrm{~N}_{4}$ (nACo). Following conclusions were reached:

1. According to average coating wear values the TiCN coating showed estimately $15-17 \%$ higher wear than nACRo and nACo.

2. It is difficult to differentiate between nACRo and nACo where nACRo could have in some cases excellent wear resistance and it could be also most worn coating.

3. Industrial field test show correlation to the ratio elastic strain to failure H/E. It is important to keep the stress level inside the coating as low as possible using coatings with low modulus of elasticity, maintaining sufficient hardness to provide high wear resistance.

4. Reciprocating sliding test results, ratios $\mathrm{H} / \mathrm{E}^{2}$ and $\mathrm{H}^{3} / \mathrm{E}^{2}$ do not show correlation with the industrial field test results.

\section{Acknowledgements}

Financial contribution from the Estonian R\&D program "Materials technology" is acknowledged for supporting the project "Advanced thin hard coatings in tooling” number AR12134. The work has been partially supported by the graduate school "Functional materials and technologies" receiving funding from the European Social Fund under project 1.2.0401.09-0079 in Estonia.

\section{REFERENCES}

1. Klocke, F., Raedt, H. W. Formulation and Testing of Optimised Coating Properties with Regard to Tribological Performance in Cold Forging and Fine Blanking Applications International Journal of Refractory Metals \& Hard Materials 19 2001: pp. 495-505.

2. Klocke, F., Maßmann, T., Gerschwiler, K. Combination of PVD Tool Coatings and Biodegradable Lubricants in Metal Forming and Machining Wear 259 2005: pp. 1197-1206.

3. Lugscheider, E., Bobzin, K., Pinero, C., Klocke, F., Massmann, T. Development of a Superlattice (Ti,Hf,Cr)N Coating for Cold Metal Forming Applications Surface and Coatings Technology 177-178 2004: pp. 616-622.

4. Bobzin, K., Bagcivan, N., Immich, P., Warnke, C., Klocke, F., Zeppenfeld, C., Mattfeld, P. Advancement of a Nanolaminated TiHfN/CrN PVD Tool Coating by a NanoStructured CrN Top Layer in Interaction with a Biodegradable Lubricant for Green Metal Forming Surface \& Coatings Technology 203 2009: pp: 3184-3188.

5. Straffelini, G. Bizzotto, G., Zanon, V. Improving the Wear Resistance of Tools for Stamping Wear 269 2010: pp. 693-697.
6. Leyland, A., Matthews, A. On the Significance of the $H / E$ Ratio in Wear Control: a Nanocomposite Coating Approach to Optimised Tribological Behavior Wear 246 2000: pp. 1-11.

7. Hogmark, S., Jacobson, S., $\quad$ Larsson, M. Design and Evaluation of Tribological Coatings Wear 246 2000: pp: 20-33.

8. Bay, N., Azushima, A., Groche, P., Ishibashi, I., Merklein, M., Morishita, M., Nakamura, T., Schmid, S., Yoshida, M. Environmentally Benign Tribo-systems for Metal Forming CIRP Annals - Manufacturing Technology 59 2010:pp. $760-780$.

9. http://www.oerlikon.com/balzers/en/

10. Lind, L., $\quad$ Peetsalu, P., $\quad$ Põdra, P., $\quad$ Adoberg, E., Veinthal, R., Kulu, P. Description of Punch Wear Mechanism During Fine Blanking Process Proceedings of 7 th International Conference of DAAAM 2010: pp. 504-509.

11. Peetsalu, P., Saarna, M., Adoberg, E., Kulper, E., Lind, L., Kulu, P. Evaluation of Punch Wear Resistance During Industrial Test Acta Metallurgica Slovaca Conference 1 2010: pp. 105-110.

12. Oliver, W. C., Pharr, G. M. An Improved Technique for Determining Hardness and Elastic Modulus Using Load and Displacement Sensing Indentation Experiments Journal of Materials Research 7 1992: pp. 1564-1583.

13. Technical Specification CEN/TS 1071-7:2003, Advanced Technical Ceramics - Methods of Test for Ceramic Coatings - Part 7: Determination of Hardness and Young's Modulus by Instrumented Indentation Testing.

14. Technical Specification CEN/TS 1071-8: 2004, Advanced Technical Ceramics - Methods of Test for Ceramic Coatings - Part 8: Rockwell Indentation Test for Evaluation of Adhesion.

15. Verein Deutscher Ingenieure Normen, VDI 3198, VDIVerlag, Dusseldorf, 1991.

16. Standard EVS-EN 1071-12:2010. Advanced Technical Ceramics - Methods of Test for Ceramic Coatings - Part 12: Reciprocating Wear Test.

17. Faga, M. G., Gautier, G., Calzavarini, R., Perucca, M., Aimo Boot, E., Cartasegna, F., Settineri, L. AlSiTiN Nanocomposite Coatings Developed Via Arc Cathodic PVD: Evaluation of Wear Resistance Via Tribological Analysis and High Speed Machining Operations Wear 263 2007: pp. $1306-1314$.

18. Musil, J., $\quad$ Kunc, F., $\quad$ Zeman, H., $\quad$ Poláková, H. Relationships Between Hardness, Young's Modulus and Elastic Recovery in Hard Nanocomposite Coatings Surface and Coatings Technology 154 2002: pp. 304-313.

19. Joslin, D. L., Oliver, W. C. A New Method for Analyzing Data from Continuous Depth-sensing Microindentation Tests Journal of Materials Research 5 (1) 1990: pp 123-126.

20. Tsui, T. Y., Pharr, G. M., Oliver, W. C., Bhatia, C. S., White, R. L., Anders, S., Anders, A., Brown, I. G. Nanoindentation and Nanoscratching of Hard Carbon Coatings for Magnetic Disks MRS Proceedings 1995:pp. 383-447.

21. Wiklund, U., Gunnars, J., Hogmark, S. Influence of Residual Stresses on Fracture and Delamination of Thin Hard Coatings $\quad$ Wear 232 1999: pp. 262-269.

22. Gerth, J., $\quad$ Larsson, M., $\quad$ Wiklund, U., $\quad$ Riddar, F., Hogmark, S. On the Wear of PVD-coated HSS Hobs in Dry Gear Cutting Wear 266 2009: pp. 444-452. 